Part of Journal of Research of the National Bureau of Standards, Volume 26, January 1941

\title{
HYDROLYSIS OF TURANOSE IN ALKALINE SOLUTION ${ }^{1}$
}

\author{
By Horace S. Isbell
}

\section{ABSTRACT}

Turanose (3- $\alpha$ - $d$-glucopyranosido- $d$-fructose) differs from the more common disaccharides in that the glycosidic union is on the carbon adjacent to the reducing group. The proximity of the reducing group influences the stability of the glycosidic union and causes the disaccharide to be particularly susceptible to alkaline hydrolysis. On treatment with limewater, turanose undergoes hydrolysis rather than a normal Lobry de Bruyn interconversion. In the presence of oxygen, in alkaline solution, the sugar is hydrolyzed in large measure and the resulting glucose and fructose are oxidized to arabonic acid. On the other hand, lactulose $(4-\beta$ - $d$-galactopyranosido- $d$-fructose) is relatively stable to alkaline hydrolysis, and when treated with oxygen in solution containing potassium hydroxide it yields the salt of a disaccharide acid, presumably $3-\beta-d$-galactopyranosido- $d$ arabonic acid. The difference in the behavior of the two sugars illustrates the importance of the location of the glycosidic union in relation to the behavior of the sugars in alkaline solution. The location of the glycosidic union also affects the amount of reduction with alkaline copper reagents. Copper-reducing values by the Munson-Walker method are reported for turanose at several concentrations

\section{CONTENTS}

I. Structure of turanose

II. Lobry de Bruyn interconversion reaction

III. Alkaline hydrolysis of disaccharides

IV. Copper-reducing power of turanose and other disaccharides_.

V. Experimental details_._.

1. Preparation of the sugars

2. Alkaline hydrolysis of turanose in the presence of nitrogen $\ldots \ldots \ldots 4$

3. Oxidation of turanose, lactulose, and levulose in alkaline solution $\quad 45$

VI. References

\section{STRUCTURE OF TURANOSE}

For some time doubt has existed concerning the structure of the disaccharide, turanose, obtained by the partial hydrolysis of the trisaccharide, melezitose. In 1926 Zemplén and Braun [1] ${ }^{2}$ prepared hendecamethylmelezitose and showed that on hydrolysis it gives 2,3,4,6-tetramethyl- $d$-glucose and a sirupy trimethyl- $d$-fructose which Zemplén and Braun concluded was 1,3,4-trimethyl-d-fructose. The separation of 2,3,4,6-tetramethyl-d-glucose and 1,3,4-trimethyl-d-fructose required that turanose be either a 5 - $d$-glucopy-

1 This paper was presented before the Division of Sugar Chemistry and Technology of the American Chemical Society at Detroit, Mich., September 1940.

2 Figures in brackets indicate the literature references at the end of this paper. 
ranosido- $d$-fructose or a $6-d$-glucopyranosido- $d$-fructose. Previously Bridel and Aagaard [2] had shown that the glucosidic group has the alpha configuration. In 1931 Pacsu [3] prepared a tri-triphenylmethyl derivative of turanose which he considered as evidence of the presence of three primary hydroxyl groups. From the work of Zemplén and Braun in conjunction with his tri-triphenylmethyl derivative, Pacsu concluded that turanose is 5 - $\alpha$ - $d$-glucopyranosido- $d$-fructose. Subsequently Pacsu [4] reported the preparation of four octaacetates of turanose. The existence of four crystalline acetates of turanose could not be explained if the 5- $\alpha$ - $d$-glucopyranosido- $d$-fructose structure were correct, unless the assumption were made that some of the acetates were other than the open-chain and pyranoid types. At that time Pacsu concluded that two of the acetates comprise a pair of diastereoisomeric orthoester derivatives of turanose acetate, and that an orthoester structure accounted for the existence of the four acetates. In 1937 Cramer and Pacsu [5] reported a fifth octaacetate and noted the similarity of the supposed orthoester derivatives of turanose to the normal $d$-fructose acetates. In light of this similarity and a difference in the properties of crystalline 1,3,4-trimethyl-d-fructose [6] from the properties of the sirupy trimethyl-d-fructose of Zemplén and Braun, Pacsu and Cramer [7] stated that the structure of turanose should be reinvestigated. In this connection, it is of interest to note that they apparently did not propose a new structure or state definitely that they had abandoned the $5-\alpha-d$-glucopyranosido- $d$-fructose structure.

In 1938 Isbell and Pigman [8] showed that the mutarotation reaction of levulose consists of a pyranose-furanose interconversion. They also showed that the changes in optical rotation which take place when turanose is dissolved in water are strictly analogous to those which take place when levulose is dissolved in water. It was therefore obvious that crystalline turanose contains the same modification of the sugar as crystalline levulose. Since the existence of a furanose modification of turanose was not compatible with the 5- $\alpha$ - $d$-glucopyranosido- $d$-fructose structure, the subject was discussed and an argument was advanced to show that the glucosidic union of turanose is at carbon 3.

The Isbell and Pigman argument consisted in the following points: (1) The glucosidic group is not attached to carbons 5 or 6 because the sugar is capable of existing in a furanose and a pyranose modification. (2) Turanose forms a disaccharide phenylosazone, and hence the hydroxyl on the first carbon of the $d$-fructose constitutent is free. (3) The phenylosazone of turanose is different from the phenylosazones of maltose and cellobiose (4- $d$-glucopyranosido- $d$-glucosazones), and therefore the glucosidic group is not attached to carbon 4 . These points limited the position of the glucosidic group to carbon 3 , and inasmuch as there was no reason to doubt the validity of the alpha con- 
figuration and the pyranoid ring of the glucosidic group, Isbell and Pigman proposed the structure represented by formula $I$.

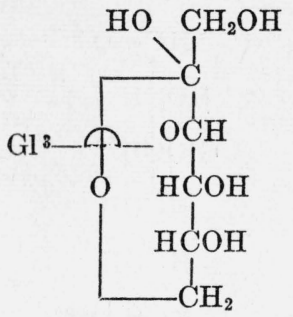

I. $3-\alpha-d$-glucosido- $d$ fructose (turanose).

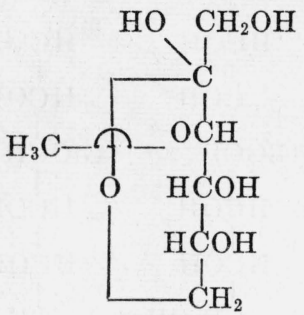

II. 3-Methyl- $d$ fructose.

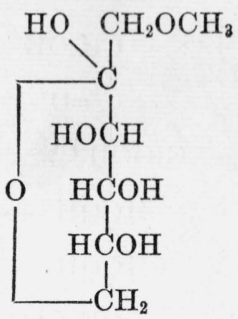

III. 1-Methyl- $d$ fructose.

The argument for the 3- $\alpha$ - $d$-glucopyranosido- $d$-fructose structure depends on the validity of the postulate that a 1- $d$-glucopyranosido- $d$ fructose would not form a disaccharide osazone, whereas a $3-d$-glucopyranosido- $d$-fructose would. Previous to the Isbell and Pigman publication, Ohle [9] had found that 1-methyl- $d$-fructose (formula III) does not give a 1-methyl- $d$-fructose osazone, whereas Freudenberg and Hixon [10] had found that 3-methyl- $d$-fructose (formula II) does. All precognition supported the postulate that substitution on carbon 1 inhibits osazone formation, but that substitution on carbon 3 does not inhibit osazone formation. Furthermore, Helferich and Bredereck [11] had reported that the sugar obtained by the deacetylation of octaacetyl-1- $\beta$ - $d$-glucosido- $d$-fructose, when heated with phenylhydrazine, gives a very small quantity of $d$-glucosazone. Helferich and Bredereck did not obtain a disaccharide osazone even though their experimental conditions were like those used for the preparation of turanose osazone. Later Pacsu, Wilson, and Graf [12] reinvestigated the reaction of $1-\beta-d$-glucopyranosido- $d$-fructose with phenylhydrazine, and in agreement with the result of Helferich and Bredereck, found that on prolonged heating $1-\beta-d$-glucosido- $d$-fructose forms a small quantity of $d$-glucosazone. Pacsu, Wilson, and Graf applied essentially the same argument as that originated by Isbell and Pigman and likewise arrived at the $3-\alpha-d$-glucosido- $d$-fructose structure.

By inspection of formula I it will be observed that the glycosidic group in turanose is attached to the carbon adjacent to the carbonyl group. Since turanose is the only naturally occurring disaccharide in which this relationship is found, it seemed desirable to compare the reactions of turanose with those of other disaccharides.

\section{LOBRY DE BRUYN INTERCONVERSION REACTION}

As shown by the classical work of Lobry de Bruyn and van Ekenstein [13] and Nef [14], when $d$-fructose is treated with alkali it is converted in part to glucose and mannose. One might anticipate that the aldehydo form of turanose would yield, according to the following

\footnotetext{
${ }^{3} \mathrm{Gl}$ is used to represent the $\alpha$ - $d$-glucosido group.
} 
diagram, 3- $\alpha$ - $d$-glucosido- $d$-glucose (formula VI) and 3- $\alpha$ - $d$-glucosido$d$-mannose (formula VII). However, when turanose was treated<smiles>O=C(CO)C(Cl)C(O)C(O)CO</smiles>

IV. Aldehydoturanose $(3-\alpha-d$-glucosido- $d$-fructose)<smiles>O=C(O)C(O)C(O)C(O)C(O)C(O)CO</smiles>

VIII. Lactulose<smiles>O=C(O)C(Cl)C(O)C(O)CO</smiles>

V. Turanose 1,2 -enediol

IX. Lactulose 1,2-enediol<smiles>O=CC(O)C(Cl)C(O)C(O)CO</smiles><smiles>O=CC(O)C(O)C(O)C(O)CO</smiles>

VI. Aldehydo3 - $\alpha$-d-glucosido-d-glucose

VII. Aldehydo3 - $\alpha$ - $d$-glucosido-d-mannose<smiles>O=CC(O)C(O)C(O)C(O)CO</smiles>

X. Lactose (aldehydo modification)
XI. Aldehydo4- $\beta$ - $d$-galactosido$d$-mannose

with calcium hydroxide at $35^{\circ} \mathrm{C}$, under the conditions which Wolfrom and Lewis [15] found to be most favorable for the interconversion of tetramethyl ethers of $d$-glucose, $d$-mannose, and $d$-fructose, the solution turned dark and it was not possible to isolate a crystalline product. Since there was evidence of decomposition, the reaction of the sugar with lime water was investigated at a lower temperature. At $20^{\circ} \mathrm{C}$ the solution of turanose remained clear for several days, and it was possible to observe the change in optical rotation. For comparison, measurements were made also with lactulose (4- $\beta-d$-galactosido- $d$-fructose) (formula VIII). The changes in optical rotation observed for the two sugars are represented by the curves given in figure 1. The increase in dextrorotation displayed by the lactulose solution is in accord with a normal Lobry de Bruyn interconversion; the reaction is merely the reverse of that used for the preparation of lactulose from lactose [16]. The results obtained with the turanose solution, however, cannot be explained by a Lobry de Bruyn interconversion, because the 3- $\alpha-d$-glucosido- $d$-mannose and the $3-\alpha-d$ glucosido- $d$-glucose which would be formed are more dextrorotatory than turanose and would require an increase in dextrorotation rather than the observed decrease. The decrease requires the formation of a levorotatory substance or the elimination of a strongly dextrorotatory group. If the disaccharide were hydrolyzed the dextrorotatory

$4 \mathrm{Gl}$ is used to represent the $\alpha-d$-glucosido group.

${ }^{5} \mathrm{Gal}$ is used to represent the $\beta$-d -galactosido group. 
$\alpha$ - $d$-glucosido group would be eliminated and an equimolecular mixture of $d$-glucose and $d$-fructose would result. This would account for the change in optical rotation and is in harmony with other work relating to the stability of certain disaccharides in alkaline solution.

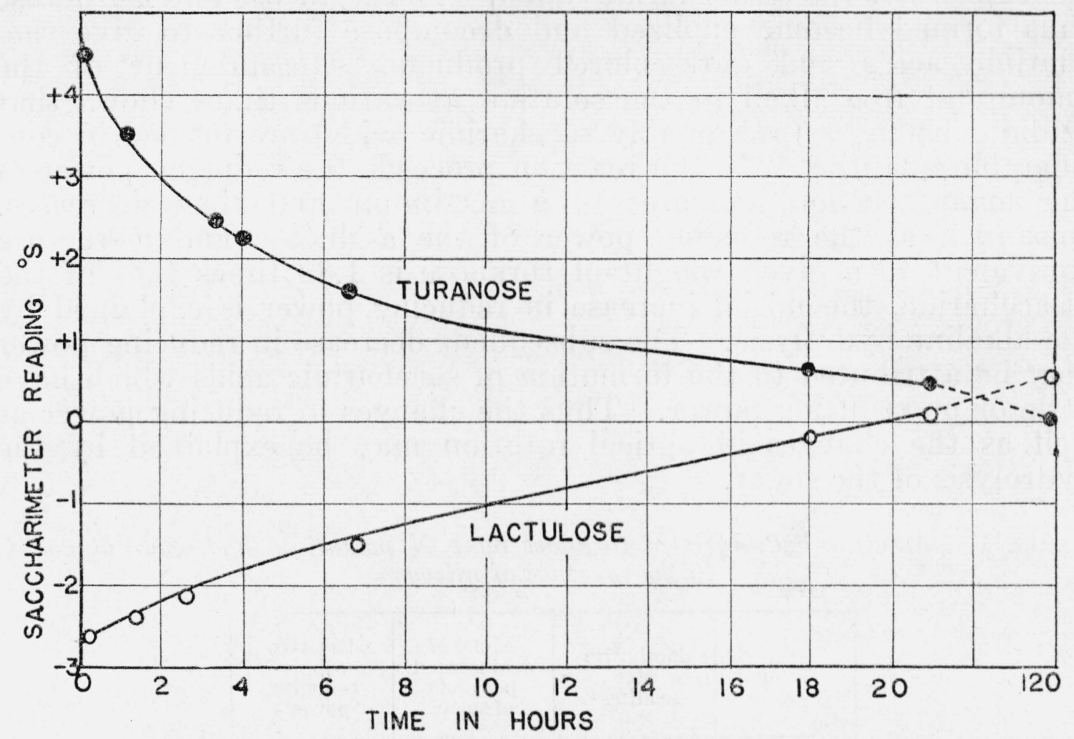

FIGURE 1.-Optical rotations of 1-percent solutions of turanose and lactulose in 0.04 $N$ calcium hydroxide at $20^{\circ} \mathrm{C}$.

\section{ALKALINE HYDROLYSIS OF DISACCHARIDES}

From an extensive investigation of the sugars in alkaline solution, Evans and coworkers $[17,18]$ came to the conclusion that "it is possible for alkaline hydrolysis of oligosaccharides to occur in molecules where the biosidic link exists either in the form al-0. $\mathrm{C}=$, or where the structure can be transformed by the alkaline medium to assume that arrangement." The 2,3-enediol of turanose (formula XII) would contain the ${ }^{\mathrm{Gl}-\mathrm{O}-\mathrm{C}=}$ group, and according to the theory of Evans and coworkers, it should be susceptible to alkaline hydrolysis. Further evidence for the alkaline hydrolysis of turanose was obtained from a study of the sugar in the presence of potassium hydroxide.

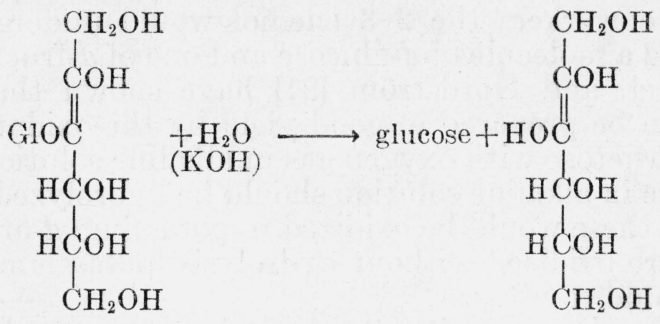

XII. Turanose 2,3-enediol. XIII. Fructose 2,3-enediol. 
When a solution of turanose in $1 \mathrm{~N}$ potassium hydroxide was allowed to stand in the absence of oxygen, the solution turned brown, and the optical rotation decreased to zero and finally became levorotatory (table 1). These observations are explained satisfactorily by the rupture of the disaccharide union. The $d$-glucose and $d$-fructose thus formed become enolized and decompose further to give saccharinic acids and dark-colored products. Measurement of the amount of free alkali in the solution at various times shows that acidic substances (presumably saccharinic acids) are formed in considerable quantity. As the reaction proceeds the reducing power of the sugar solution increases to a maximum and then decreases. Inasmuch as the reducing power of the $d$-glucose and $d$-fructose equivalent to a given weight of turanose is 1.88 times that of the disaccharide, the initial increase in reducing power is explained by the alkaline hydrolysis. The subsequent decrease in reducing power may be attributed to the formation of saccharinic acids which have little or no reducing power. Thus the changes in reducing power as well as the changes in optical rotation may be explained by the hydrolysis of the sugar.

TABLE 1.-Alkaline hydrolysis of turanose by $1 \mathrm{~N}$ potassium hydroxide at $25^{\circ} \mathrm{C}$ in the presence of nitrogen

\begin{tabular}{|c|c|c|c|}
\hline Time & $\begin{array}{c}\text { Saccharim- } \\
\text { eter } \\
\text { reading 1 }\end{array}$ & $\begin{array}{c}\text { Moles of } \\
\text { acid formed } \\
\text { per mole } \\
\text { of sugar }\end{array}$ & $\begin{array}{c}\text { Relative } \\
\text { copper- } \\
\text { reducing } \\
\text { power }\end{array}$ \\
\hline Minutes & $\circ S$ & & \\
2 & +15.41 & 0 & 1.000 \\
30 & +10.73 & .11 & 1.054 \\
77 & +6.53 & .25 & 1.077 \\
150 & +3.30 & .35 & 1.080 \\
300 & +1.43 & .42 & 1.060 \\
715 & +0.99 & -.451 & $\mathbf{0 . 9 0 7}$ \\
1,040 & -1.01 & .51 & \\
\hline
\end{tabular}

1 Samples of the solution were diluted and acidified before the saccharimeter readings were made.

2 Based on the copper-reducing power of the first sample as unity.

Additional experiments, however, were devised to confirm the existence of the hydrolytic reaction. The work of Nef [14] and others $[19,20]$ has shown that the oxidation of reducing sugars in alkaline solution yields products which throw light on the molecular changes. Presumably turanose in alkaline solution gives 1-2 and 2-3 enediols. According to the theory of Nef, the 1-2 enediol would give on oxidation formic and $2-d$-glucosido- $d$-arabonic acids, while according to the ideas of Evans and coworkers the 2-3 enediol would undergo hydrolysis readily and give a molecule of $d$-glucose and one of $d$-fructose. Spengler, Pfannenstiel, and Nordström [21] have shown that potassium $d$-arabonate can be prepared in good yield by the oxidation of either $d$-glucose or $d$-fructose with oxygen gas in alkaline solution. Hence, if the disaccharide in alkaline solution should be hydrolyzed to $d$-glucose and $d$-fructose, these would be oxidized to potassium $d$-arabonate; but if the sugar were oxidized without hydrolysis, potassium $d$-glucosido$d$-arabonate would result.

Oxidation experiments with levulose, lactulose, and turanose in alkaline solution showed marked differences. Equimolecular quantities $(0.17 \mathrm{~mole})$ of levulose and of turanose gave 2.9 and $1.8 \mathrm{~g}$, respec- 
tively, of crystalline potassium $d$-arabonate, while lactulose did not yield any crystalline potassium $d$-arabonate. The separation of potassium $d$-arabonate after the alkaline oxidation of turanose shows conclusively that under the conditions of the experiment the disaccharide union is broken, at least in part. The changes in optical rotation, copper-reducing power, and acidity in the course of the oxidations of turanose levulose and lactulose, by oxygen are given in table 2.

TABLE 2.-Oxidation of sugars by oxygen in alkaline solution at $25^{\circ} \mathrm{C}$.

\begin{tabular}{|c|c|c|c|}
\hline \multicolumn{4}{|c|}{ TURANOSE (3- $\alpha$ - $d$-glucosido- $d$-fructose) } \\
\hline Time & $\begin{array}{l}\text { Saccharimeter } \\
\text { reading } 1\end{array}$ & $\begin{array}{l}\text { Moles of } \\
\text { acid } \\
\text { formed } \\
\text { per mole } \\
\text { of sugar }\end{array}$ & $\begin{array}{l}\text { Copper } \\
\text { reducing } \\
\text { power } \\
\text { of the } \\
\text { solution }\end{array}$ \\
\hline $\begin{array}{c}\text { Minuies } \\
3 \\
30 \\
120 \\
150 \\
225 \\
300 \\
375 \\
515 \\
1,230\end{array}$ & $\begin{aligned} \circ S \\
+15.31 \\
+10.81 \\
+5.15 \\
+4.73 \\
+3.32 \\
+2.84 \\
+2.48 \\
+2.29 \\
+0.98\end{aligned}$ & $\begin{array}{l}0 \\
0.12 \\
.44 \\
.51 \\
.66 \\
.78 \\
.85 \\
1.00 \\
1.22\end{array}$ & $\begin{array}{l}1.000 \\
1.061 \\
1.031 \\
1.025 \\
0.952 \\
.877 \\
.800 \\
.635 \\
.484\end{array}$ \\
\hline \multicolumn{4}{|c|}{ LEVULOSE ( $d$-fructose) } \\
\hline $\begin{array}{r}2 \\
30 \\
75 \\
150 \\
220 \\
300 \\
516 \\
1,320\end{array}$ & $\begin{array}{r}-9.73 \\
-8.42 \\
-6.50 \\
-4.20 \\
-2.38 \\
-1.15 \\
+0.42 \\
+.46\end{array}$ & $\begin{array}{l}0 \\
0.12 \\
.34 \\
.44 \\
.68 \\
.83 \\
.97 \\
1.02\end{array}$ & $\begin{array}{l}1.000 \\
0.891 \\
.669 \\
.584 \\
.418 \\
.293 \\
.150 \\
.125\end{array}$ \\
\hline \multicolumn{4}{|c|}{ LACTULOSE (4- $\beta$ - $d$-galactosido- $d$-fructose) } \\
\hline $\begin{array}{r}3 \\
30 \\
75 \\
150 \\
225 \\
300 \\
575 \\
810 \\
1,350\end{array}$ & $\begin{array}{r}-10.64 \\
-9.14 \\
-7.24 \\
-4.64 \\
-2.49 \\
-1.01 \\
+1.80 \\
+2.83 \\
+3.43\end{array}$ & $\begin{array}{r}0.07 \\
.16 \\
.32 \\
.45 \\
.57 \\
.69 \\
.88 \\
1.09\end{array}$ & $\begin{array}{l}1.000 \\
0.977 \\
.926 \\
.830 \\
.762 \\
.700 \\
.585 \\
.488 \\
.396\end{array}$ \\
\hline
\end{tabular}

1 Samples of the solution were acidified and diluted to a definite volume before the saccharimeter readings were made.

The copper-reducing powers of the levulose and lactulose solutions decrease from the beginning of the experiment, whereas the copperreducing power of the turanose solution increases to a maximum and then decreases. The increase in reducing power observed for turanose is similar to that found in the absence of oxygen and presumably arises from the hydrolysis of the disaccharide. The optical rotations of the levulose and lactulose solutions change in the direction that would be anticipated for the change accompanying the conversion of levulose to potassium arabonate and of lactulose to potassium 3- $d$-galactosido- $d$ arabonate. The optical rotation of the turanose solution changes in the opposite direction and may be explained satisfactorily by the rup- 
ture of the disaccharide union and the subsequent oxidation of the liberated glucose and fructose.

Before considering the reactions of turanose further, it is of interest to note the behavior of melezitose in alkaline solution in the presence of oxygen. Melezitose differs from turanose in that the reducing group in the fructose constituent is blocked by combination with a glucosidic group, and hence it cannot form an enediol. When a sample of melezitose was dissolved in aqueous potassium hydroxide at $20^{\circ} \mathrm{C}$ in the presence of oxygen, the optical rotation did not change in the course of three days, and after this time nearly all of the melezitose was recovered unchanged. The stability of melezitose under conditions which lead to the cleavage of turanose is further evidence that the sensitivity of turanose to alkaline hydrolysis is related to the presence of a free reducing group in the vicinity of the glycosidic union. It seems probable that similar glycosidic linkages in other naturally occurring products will prove relatively stable to alkaline hydrolysis as long as the carbonyl group is not free. Partially hydrolyzed substances containing free reducing groups in the vicinity of the glycosidic unions, however, will prove susceptible to alkaline hydrolysis.

\section{COPPER-REDUCING POWER OF TURANOSE AND OTHER DISACCHARIDES}

A comparison of the reducing powers of turanose with those of other sugars provides information concerning the behavior of the disaccharides in alkaline solution. Previously Isbell, Pigman, and Frush [22] determined the reducing powers of 32 sugars, using a modified Scales method and a copper-citrate reagent buffered with sodium carbonate. Turanose was found to have the lowest reducing power.

It will be noted from the values given in table 3 that the relative molecular reducing powers of the 4-hexosidohexoses and 6-hexosidohexoses are about 1.4 and 1.2 , respectively, while the molecular reducing power of turanose is only 0.8. This low reducing power must arise from the unusual structure of turanose. The oxidation of a disaccharide by an alkaline copper reagent can be considered to involve (1) the oxidation and degradation of the reducing portion of the molecule, and (2) the hydrolysis of the disaccharide union and the subsequent oxidation of the fragments set free by hydrolysis. The oxidation and degradation of the reducing portion of the molecule are restricted by the position of the disaccharide union. Without hydrolysis of the disaccharide union, a 3-glucosidofructose, such as turanose, might yield formaldehyde and 2-glucosidoarabinose; whereas, a 4-glucosidofructose might yield formaldehyde, glycol aldehyde, and 2-glucosidoerythrose. Because of the blocking action of the glycosidic group on carbon 3, turanose would give fewer reducing fragments without hydrolysis than any of the other disaccharides listed in table 3. For this reason it might be expected to give the lowest reducing power with reagents which do not cause extensive hydrolysis. The reagents ordinarily used for the determination of reducing sugars, however, are strongly alkaline and, from the behavior of the sugar in aqueous potassium hydroxide one might anticipate considerable hydrolysis. If turanose were hydrolyzed completely before oxidation, the molecular reducing value should approximate that of one molecule of glucose and one molecule of fructose, namely 
2.1. The low reducing power (0.8), which was found experimentally, clearly shows that, under the conditions used, the sugar is not completely or even largely hydrolyzed prior to oxidation. Supposedly oxidation and hydrolytic reactions take place simultaneously. At low temperatures in the absence of a vigorous oxidizing agent, the hydrolytic reaction predominates. But at boiling temperatures in the presence of a copper reagent, the sugar is oxidized in large measure without hydrolysis, and the product does not appear to be hydrolyzed and degraded further. In other words, the low reducing power of turanose seems to arise from the formation of some product which is relatively inert in respect to the alkaline copper reagent. This product may be 2-glucosidoarabonic acid which would arise from turanose 1,2-enediol (formula V). The 2,3-enediol (formula XII) would be susceptible to alkaline hydrolysis. Since the relative molecular reducing powers of the 4- and 6-hexosidohexoses listed in table 3 are greater than 1, the glycosidic portion of these disaccharides must contribute to the reducing power, and some hydrolysis must take place. Cleavage of the disaccharide may require that the reducing part of the molecule be first degraded to an intermediate substance which can give the $\mathrm{Gl} \mathrm{O}-\mathrm{C}=$ group that Evans and coworkers [18] have shown to be susceptible to alkaline hydrolysis. In substances containing this group, degradation and hydrolytic reactions may take place simultaneously. Probably the low reducing power of turanose is caused by the lack of the extensive degradation reactions and not by a lack of hydrolysis. The comparatively low reducing power of the 6-hexosidohexoses, on the other hand, may be explained by a lack of sensitivity to alkaline hydrolysis. This lack of sensitivity to alkaline hydrolysis may be due to the location of the glycosidic union at a point which is unfavorable for the formation of a $\mathrm{Gl}-\mathrm{O}-\mathrm{C}=$ group.

Measurements of the reducing power of turanose under different conditions gave results which varied considerably and showed that the amount of reduction depends in large measure on the method employed. The relative reducing power of turanose on a weight basis by the Munson-Walker method [23] (table 4) varies with concentration from about 0.53 to 0.56 ; by a modified Scales method [22] the relative reducing power is only 0.41 . Presumably the higher value obtained with the Munson-Walker method is due to more hydrolysis, caused by the higher alkalinity of the reagent.

It was mentioned, in connection with the interpretation of the analytical data for the alkaline hydrolysis of turanose, that when a turanose solution is treated with alkali the copper-reducing power increases, and that this increase in reducing power is caused by the hydrolysis of the sugar. Since on hydrolysis one molecule of turanose yields one molecule of glucose and one molecule of fructose, the reducing power of hydrolyzed turanose is equal to that of a corrresponding quantity of invert sugar. A calculation from the Munson-Walker values $[23,24]$ for the reducing power of invert sugar shows that the quantity of invert sugar which would be obtained by the hydrolysis of $0.1 \mathrm{~g}$ of turanose would yield $0.2274 \mathrm{~g}$ of cuprous oxide. This is 1.88 times the quantity of cuprous oxide produced by $0.1 \mathrm{~g}$ of turanose. 
TABLE 3.-Relative reducing powers of disaccharides ${ }^{1}$

\begin{tabular}{|c|c|c|}
\hline \multirow{2}{*}{ Sugar } & \multicolumn{2}{|c|}{$\begin{array}{l}\text { Relative reducing } \\
\text { power. Glucose }=1\end{array}$} \\
\hline & $\begin{array}{l}\text { Molecular } \\
\text { basis ? }\end{array}$ & $\begin{array}{c}\text { Weight } \\
\text { basis }\end{array}$ \\
\hline 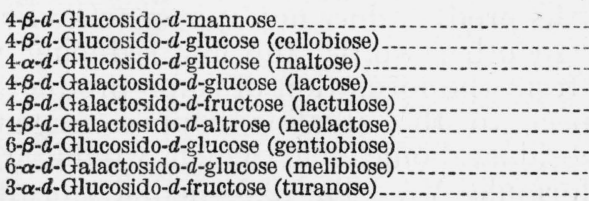 & $\begin{array}{l}1.49 \\
1.47 \\
1.39 \\
1.42 \\
1.39 \\
1.44 \\
1.20 \\
1.18 \\
0.77\end{array}$ & $\begin{array}{l}0.78 \\
.77 \\
.73 \\
.75 \\
.73 \\
.76 \\
.63 \\
.62 \\
.40\end{array}$ \\
\hline
\end{tabular}

1 Values determined by Isbell, Pigman, and Frush [22] with an alkaline copper-citrate reagent.

2 The ratio of the reduction produced by the quantity of the sugar, molecularly equivalent to $15 \mathrm{mg}$ of $d$-glucose, to that produced by $15 \mathrm{mg}$ of $d$-glucose.

TABLE 4.-Comparative reducing power of turanose and glucose (Munson-Walker method)

\begin{tabular}{|c|c|c|c|}
\hline Turanose & $\begin{array}{c}\text { Milligrams } \\
\text { of cuprous } \\
\text { oxide pro- } \\
\text { duced by } \\
\text { sample }\end{array}$ & $\begin{array}{c}\text { Glucose 1 } \\
\text { equivalent } \\
\text { to same } \\
\text { quantity of } \\
\text { cuprous oxide }\end{array}$ & $\begin{array}{c}\text { Relative } \\
\text { reducing } \\
\text { ratio.2 } \\
\text { Glucose=1 } \\
\text { (weight basis) }\end{array}$ \\
\hline$M g$ & 121.1 & 52.9 & $\mathbf{0 . 5 2 9}$ \\
100 & 239.4 & 107.9 & .539 \\
200 & 299.8 & 137.3 & .549 \\
250 & 414.5 & 195.7 & .559 \\
350 & 4.5 & \\
\hline
\end{tabular}

1 Data from the work of Hammond [24].

2 The "relative reducing ratio" is the ratio of the weight of dextrose to the weight of turanose required to give like reduction.

\section{EXPERIMENTAL DETAILS}

\section{PREPARATION OF THE SUGARS}

Melezitose.-The melezitose was prepared in 1928 in collaboration with C. S. Hudson from some melezitose honey [25] kindly supplied by the Office of Bee Culture Investigations, United States Department of Agriculture. From $250 \mathrm{~kg}$ of melezitose honey $13 \mathrm{~kg}$ of pure melezitose was obtained. A part of the material was recrystallized and used in this investigation. In a 4-percent aqueous solution it gave $[\alpha]_{D}^{20}=+88.2$.

Turanose.-The turanose was prepared by the method of Hudson and Pacsu [26]. Crystallization was induced by seed crystals kindly supplied by D. H. Brauns, who was the first [26, p. 2521] to discover and separate crystalline turanose. The sugar was recrystallized by concentrating an aqueous solution containing $100 \mathrm{~g}$ of turanose to a sirup $\left(n_{D}^{20}=1.490\right)$ which was dissolved in $100 \mathrm{ml}$ of hot methyl alcohol. The clear alcoholic solution was allowed to cool, after which it was seeded and kept for several days while crystallization took place. In a 4-percent aqueous solution, the resulting crystals gave $[\alpha]_{D}^{20}=+27.3$ initially, changing in the course of an hour to an equilibrium value of +75.8 . 
Lactulose.-The lactulose was prepared by the method of Montgomery and Hudson [16] without the use of seed crystals. The product was recrystallized by essentially the same procedure as that used for turanose. In 4-percent aqueous solution the material gave $[\alpha]_{D}^{20}=-11.9$ initially, changing in several hours to -50.7 .

\section{ALKALINE HYDROLYSIS OF TURANOSE IN THE PRESENCE OF NITROGEN}

A sample of pure crystalline turanose $(5.7 \mathrm{~g})$ was dissolved in 50 $\mathrm{ml}$ of $1 \mathrm{~N}$ potassium hydroxide solution, with stirring, while a small stream of nitrogen was bubbled through the solution, which was kept at $25^{\circ} \mathrm{C}$. From time to time, 5-ml samples of the alkaline solution were taken and mixed quickly with $10 \mathrm{ml}$ of $0.5 \mathrm{~N}$ hydrochloric acid. Time was measured for each sample, beginning with the dissolution of the sugar and ending with the addition of the hydrochloric acid. The optical rotation of the acidified solution was read with a Bates saccharimeter in a $2-\mathrm{dm}$ tube at $20^{\circ} \mathrm{C}$. A $10-\mathrm{ml}$ portion of the solution used for the optical rotation measurement, was transferred to a $50-\mathrm{ml}$ graduated flask and titrated with $0.2 \mathrm{~N}$ potassium hydroxide, using phenolphthalein as an indicator. The volume of the original sugar solution was $54 \mathrm{ml}$ and the sample for each titration corresponded to $3.33 \mathrm{ml}$ of the original sugar solution, or 0.00103 mole of sugar. After the titrations were completed, the solutions were diluted to $50 \mathrm{ml}$ and reducing-sugar determinations were made by the Munson-Walker method. The weights of cuprous oxide obtained from $20 \mathrm{ml}$ of the diluted solution were divided by the weight of the cuprous oxide obtained from the sample taken at the beginning of the experiment to give the "relative copper-reducing power." The results are given in table 1.

\section{OXIDATION OF TURANOSE, LACTULOSE, AND LEVULOSE IN ALKALINE SOLUTION}

The oxidation experiments were conducted essentially like the alkaline hydrolysis described in the preceding section, except that oxygen gas was used in place of nitrogen and larger quantities were employed in order to provide material for the isolation of the product. In these measurements, 0.033 mole of the sugar was dissolved in 100 $\mathrm{ml}$ of $1 \mathrm{~N}$ potassium hydroxide, and the solution was kept saturated with oxygen. The optical rotations, moles of acid formed per mole of sugar, and the copper-reducing values were measured in the same manner as in the experiments in the presence of nitrogen. The methods are described in the preceding section, and the results are recorded in table 2 .

After the oxidation experiment had proceeded for 22 hours, the reaction was stopped by saturating the alkaline solution with carbon dioxide. To isolate the product, $50 \mathrm{ml}$ of the solution was concentrated to a sirup, which was diluted with alcohol and seeded with crystalline potassium arabonate. The sample from the levulose experiment gave $2.9 \mathrm{~g}$ of crystalline potassium arabonate, while that from the turanose experiment gave $1.8 \mathrm{~g}$. The experiment with lactulose did not yield any crystalline potassium arabonate even though a careful search was made. The product in the evaporated 
solution from the lactulose experiment was precipitated by the addition of ethyl alcohol as a light-colored sirup which has failed to crystallize. Before hydrolysis, the sirupy product did not reduce Fehling's solution. After boiling for a few minutes with aqueous hydrochloric acid, the hydrolyzed product gave a strong test for reducing sugar. These observations may be explained by the presence of a bionic acid, presumably $3-\beta-d$-galactosido- $d$-arabonic acid.

\section{REFERENCES}

[1] G. Zemplén and G. Braun, Ber. deut. chem. Ges. 59, 2230 (1926); G. Zemplén, Ber. deut. chem. Ges. 59, 2539 (1926).

[2] M. Bridel and Th. Aagaard, Compt. rend. 184, 1667 (1927); Bul. soc. chim. biol. 9, 884 (1927).

[3] E. Pacsu, J. Am. Chem. Soc. 53, 3099 (1931).

[4] E. Pacsu, J. Am. Chem. Soc. 54, 3649 (1932).

[5] F. B. Cramer and E. Pacsu, J. Am. Chem. Soc. 59, 711 (1937).

[6] W. S. Challinor, W. N. Haworth, and E. L. Hirst, J. Chem. Soc. 1934, 676.

[7] E. Pacsu and F. B. Cramer, J. Am. Chem. Soc. 59, 1059 (1937).

[8] H. S. Isbell and W. W. Pigman, J. Research NBS 20, 773 (1938) RP1104.

[9] H. Ohłe, I. Koller, and G. Berend, Ber. deut. chem. Ges. 58, 2581 (1925).

[10] K. Freudenberg and R. M. Hixon, Ber. deut. chem. Ges. 56, 2126 (1923).

[11] B. Helferich and H. Bredereck, Liebigs Ann. Chem. 465, 166 (1928).

[12] E. Pacsu, E. J. Wilson, Jr., and L. Graf, J. Am. Chem. Soc. 61, 2675 (1939).

[13] Lobry de Bruyn and S. W. Van Ekenstein, Rec. trav. chim. Pays-Bas 16, $262(1897) ; 19,1$ (1900).

[14] J. U. Nef, Liebigs Ann. Chem. 403, 204 (1914).

[15] M. L. Wolfrom and W. L. Lewis, J. Am. Chem. Soc. 50, 837 (1928).

[16] E. M. Montgomery and C. S. Hudson, J. Am. Chem. Soc. 52, 2101 (1930).

[17] W. L. Evans and M. P. Benroy, J. Am. Chem. Soc. 52, 294 (1930).

[18] H. Gehman, L. C. Kreider, and W. L. Evans, J. Am. Chem. Soc. 58, 2388 (1936).

[19] W. L. Lewis and S. A. Buckborough, J. Am. Chem. Soc. 36, 2385 (1914).

[20] J. W. E. Glattfeld, Am. Chem. J. 50, 137 (1913).

[21] O. Spengler, A. Pfannenstiel, and L. Nördstrom, Z. Wirtschaftsgruppe Zuckerind. 89, 171 (1939).

[22] H. S. Isbell, W. W. Pigman, and H. L. Frush, J. Research NBS 24, 241 (1940) RP1282.

[23] Methods of Analysis, Assoc. Offic. Agri. Chem. (Washington, D. C., 1940), 5 th edition, page 500 .

[24] L. D. Hammond, J. Research NBS 24, 579 (1940) RP1301.

[25] C. S. Hudson and S. F. Sherwood, J. Am. Chem. Soc. 42, 116 (1920).

[26] C. S. Hudson and E. Pacsu, J. Am. Chem. Soc. 52, 2519 (1930).

Washington, October 25, 1940. 